\title{
CASE OF AUTOIMMUNE HEMOLYTIC ANEMIA IN A CHILD WITH \\ NECROTIZING PNEUMONIA
}

B. Shenoy ${ }^{1}$, I . Kimin ${ }^{2}$, B . Bharath ${ }^{3}$, M. Hafis ${ }^{4}$.

${ }^{1}$ Head of Paediatric Infectious Diseases, ${ }^{2}$ Paediatric Pulmonologist ,

Fellow in Paediatric Infectious Diseases. , ${ }^{4}$ DNB Resident

Manipal Hospital, Bangalore, India.

\section{INTRODUCTION}

Even though AIHA with Mycoplasma and Viral infections are common in children, AIHA associated with pneumococcal pneumonia is a rare presentation.

\section{CASE HISTORY}

A $2 \frac{1}{2}$ years old child presented with

* Cough for 2 weeks

* Fever for 2 weeks with fast breathing.

On evaluation, he was pale, tachypnic and in respiratory distress with bronchial breathing on right side.

\section{INVESTIGATION}

* Complete blood counts showed Anemia with leucocytosis (Hb-7.9g/dl on admission and $5.9 \mathrm{~g} / \mathrm{dl}$ on next day).

* CRP was $338 \mathrm{mg} / \mathrm{dl}$.

- Peripheral smear showed normocytic hypochromic erythrocytes with few macrocytes, target cells and polychromatic cells.

* Chest X-ray showed right upper and middle lobe consolidation.
* Coombs test was positive with anti IgG/C3d.

* Auto antibodies are present at $37 \mathrm{deg} \mathrm{C}$ as well as 4 $\operatorname{deg} \mathrm{C}$ (both warm and cold antibodies).

- Blood culture was negative, but PCR was positive for Streptococcus pneumoniae.

* CT chest was done due to continuous fever spikes and persistently elevated inflammatory markers and it showed right necrotizing pneumonia with moderated empyema.

\section{MANAGEMENT}

* Child was admitted in PICU and started on HFNC initially and later shifted to BIPAP in view of worsening distress.

* Child was started on IV antibiotics ,Meropenem and Vancomycin.

* He was treated with IVIG $(1 \mathrm{~g} / \mathrm{kg})$ and laterwas transfused with 1 unit of PRBC's.

* Right Thoracotomy and Decortication with Evacuation of empyema with Lung Debridement was done.
* IV antibiotics continued for 14 days and later changed to oral therapy.

* Repeat Chest X-ray showed significant improvement.

\section{DISCUSSION}

* AIHA, though common with Mycoplasma pneumonia can be seen with Streptococcus pneumonia.

* A short course of IVIG or Corticosteroids are beneficial for severe hemolytic anemia in acute phase.

- Treatment of pneumonia itself reduces the hemolysis in due course.

\section{KEYWORDS}

Mycoplasma, Autoimmune Hemolytic Anemia Necrotizing pneumonia 